\title{
A prática da improvisação em ambientes híbridos e multiculturais: propostas para a formação do músico
}

\author{
Ana Luisa Fridman \\ (ECA/USP)
}

Resumo: $\mathrm{O}$ artigo é um recorte de uma pesquisa de doutorado em andamento, cujo tema central consiste no estudo e elaboração de propostas de improvisação que se utilizam de materiais expressivos e procedimentos musicais encontrados na música não ocidental. No artigo aqui apresentado, vamos inicialmente observar a contribuição de tais materiais a partir de sua influência na composição e na performance no ocidente desde o início do século XX. A seguir, vamos propor sua utilização para o estudo da improvisação direcionada para a formação de músicos, com algumas sugestões de exercícios.

Palavras-chave: improvisação, música não ocidental, formação do músico.

THE PRACTICE OF IMPROVISATION IN HYBRID AND MULTICULTURAL ENVIRONMENTS: PROPOSALS FOR MUSIC FORMATION

Abstract: This article is an excerpt from an ongoing doctoral research, whose central subject is a proposal for the study and practice of music improvisation that uses expressive materials and music procedures found in non-Western music. In the article presented here, we initially observe the contribution of such materials starting from their influence on the composition and performance in the West since the early twentieth century. Next, we propose its use for the study of music improvisation directed to the training of musicians, with some suggestions for exercises.

Keywords: improvisation, non-Western music, music training 


\section{O músico e a prática da improvisação}

Nos idiomas musicais aonde ocorrem as práticas de improvisação (no jazz, no flamenco, na música hindu, na improvisação livre, etc.) são utilizados diferentes procedimentos e materiais expressivos. Estes materiais são tanto as constantes características de cada idioma - configurações escalares, estruturas rítmicas, formais etc. - quanto as variáveis que se manifestam no decorrer de uma performance, que incluem toda uma série de componentes instáveis ligados às interações sonoras e expressivas.

No jazz tradicional, como exemplo desta prática, os músicos improvisam baseados em formas definidas e padrões melódico/harmônicos pré-determinados, sendo que o improvisador em geral é um músico solista no momento da improvisação'. Na música não ocidental, à exemplo das práticas mais tradicionais encontradas na Índia e em algumas regiões da África, como Gana e Tanzânia, a prática da improvisação é muitas vezes tratada de maneira ritualística, sendo que há muitos materiais - como configurações escalares fora do sistema tonal, procedimentos rítmicos como o uso da polirritmia e de compassos assimétricos, e a integração corpo/música - que podem ser expandidos na prática da improvisação em contextos multiculturais.

O objetivo primordial na formação do músico deve ser encontrar o equilíbrio entre a "nossa música" e "a música dos outros", entre o velho e o novo, entre o que é notado e o que não é, entre a tradição e seu potencial para a mudança. Improvisação dentro de um contexto de formação musical, seja aprendendo para improvisar ou improvisando para aprender, deve ser o foco central para a construção de um músico de expressão². (Campbel in: Solis; Nettl, 2009, p. 140)

\footnotetext{
1 Ressaltando que, mesmo havendo um solista, em certa medida todos os jazzistas improvisam, mesmo quando estão acompanhando o solista. Há também no jazz tradicional (Dixieland, New Orleans) momentos em que há improvisação coletiva.

2 "The ultimate aim of a musical education may be to give balance to "our music" and "their music", to the old and the new music, to what's notated and what is not, to traditions and their potential to change. Improvisation within a musical education, whether it is learning to improvise or improvise to learn, may be central to making an expressive musician."
} 
Corroborando com as ideias da musicóloga americana Patricia Campbel, consideramos a improvisação como uma prática enriquecedora na formação do músico, principalmente quando tratada sob um panorama multicultural. Citando ainda a mesma autora, Campbell observa que, como em nenhuma outra experiência, a improvisação proporciona aos estudantes uma experiência musical integral, aonde a criação, a teoria musical, a percepção e a performance se encontram em uma única prática (Campbel in: Sollis; Nettl, 2009, p. 133). Reforçando ainda mais esta ideia, citamos a observação do guitarrista inglês Derek Bailey a respeito do mesmo tema:

Considerando que a improvisação está presente em algum grau em quase todas as atividades musicais, parece-nos que a capacidade para improvisar deveria ser um requisito básico de formação para todo músico³. (Bailey, 1993, p. 66)

Observando que tal prática está presente em períodos e contextos diversos da música, vamos propor que haja um olhar sobre a improvisação como elemento de estudo para a formação do músico a partir de sua graduação. Mesmo considerando que esta prática está mais associada a cursos de performance musical, gostaríamos de ressaltar que nos referimos a todo e qualquer curso de graduação em música, independente de sua área de estudo, seja esta mais focada na música erudita, popular, cursos com ênfase na performance, composição e afins. Estamos então sugerindo a prática e o estudo da improvisação para todo e qualquer músico que ingressa no ensino formal, sendo que, neste artigo mais especificamente, nosso foco é a utilização de estruturas da música não ocidental para o estudo e a realização desta prática.

Abordando ainda a improvisação como elemento de estudo para a formação do músico, podemos inclusive questionar se o músico que ingressa em um curso de graduação sabe o que é improvisar e de que formas o músico pode desenvolver esse processo criativo.

\footnotetext{
3 "As improvisation is present in some degree in almost all music activities it would seem that the ability to improvise might be a basic part of every player's musicianship."
} 
Em nosso artigo vamos propor que a improvisação - inserida como disciplina do curso de graduação em música - seja trabalhada de forma ampla e abrangente, incorporando procedimentos inicialmente utilizados na música não ocidental para sua abordagem. No estudo da improvisação vamos propor exercícios em contextos híbridos a partir de estruturas que vamos estender para fora de seu contexto de origem. Nosso objetivo será o de contribuir para que o músico em formação possa aumentar suas possibilidades em relação à utilização da improvisação em seu caminho musical.

\section{A improvisação na música não ocidental}

A prática da improvisação é bastante encontrada em contextos da música não ocidental, sendo este um território amplo e de possibilidades diversas. Na Índia, por exemplo, aonde a música pode ser encontrada em formatos mais tradicionais no norte (música Hindustani) e mais inovadores no sul (música Carnática), a improvisação é um elemento vital nas duas regiões. Sua estrutura principal é a raga e esta está baseada em um ciclo rítmico chamado de tala. As configurações melódicas da música indiana variam bastante, sendo que há escalas com até 22 notas, definidas por um intervalo mínimo chamando de sruti. As estruturas da música indiana podem sofrer variações, sendo que sua natureza é maleável e a improvisação para os músicos indianos é um fato, um elemento primordial em sua música.

Em algumas regiões da África aonde a improvisação faz parte da prática musical, esta é muitas vezes baseada em ostinatos rítmicos que servem de base para que a improvisação aconteça. Abaixo, um exemplo de uma estrutura baseada em um ostinato, utilizada em Mali por Souleymane Traoré (conhecido por Neba Solo), instrumentista de balafon: ${ }^{4}$

\footnotetext{
${ }^{4}$ Utilizado no oeste da África, o balafon é uma espécie de xilofone que possui formato curvo, amarrações em couro e cordas, utilizando cabaças como ressonadores. É tocado com duas baquetas.
} 
Figura 1 - afinação do balafon

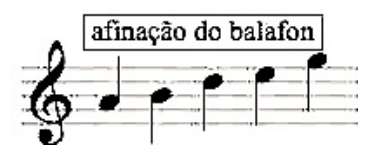

Figura 2 - ostinato para improvisação

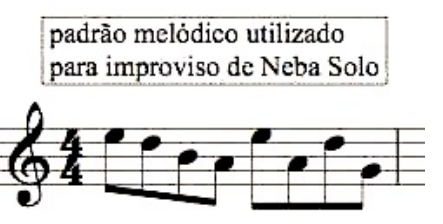

Fonte (Figuras 1 e 2): Monson, Ingrid in: Solis; Nettl, 2009, p.28

$\mathrm{Na}$ Indonésia, na música javanesa tocada na formação instrumental denominada gamelão5, a estrutura é um pouco mais restrita que na música indiana e africana, mas, mesmo mantendo a mesma configuração escalar original (chamadas de sléndro e pélog, ver Figuras 3 e 4, observando que o exemplo é uma aproximação da escala original, por não se tratar de um sistema temperado de afinação) e alguns padrões rítmicos, os músicos costumam fazer pequenas variações interpretativas quando tocam.

Figura 3 - escala pélog

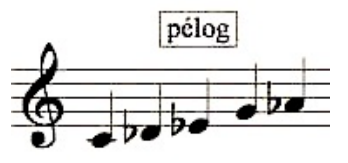

Figura 4 - escala sléndro

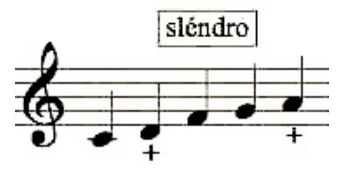

Fonte (Figuras 3 e 4): Titon, 2005, p.234

É interessante observar também que nessas culturas existe uma forte corporalidade do músico, sendo que muitas vezes a música e a dança acontecem de forma integrada na performance. Tal fato despertou a atenção de educadores

\footnotetext{
${ }^{5}$ Orquestra de instrumentos de percussão típica das ilhas da Indonésia, composta por uma variedade de metalofones, xilofones tambores e gongos.
} 
como o franco-suíço Emile-Jacques Dalcroze (1865-1950), que no início do século XX criou uma metodologia que propôs a inclusão da improvisação e da integração música/corpo como procedimentos primordiais para o estudo da música.

Foi Emile-Jacques Dalcroze quem primeiro percebeu que o ritmo musical depende absolutamente de sua consciência motora para sua expressão mais plena. Suas pesquisas levaram-no à elaboração de um sistema de integração entre movimento e ritmo projetado para desenvolver o domínio do ritmo musical. Este sistema de educação musical usa o corpo como intérprete do ritmo musical e é conhecido em todo o mundo como Euritmia ${ }^{6}$. (Findlay, 1999, p. 2)

Considerando o aspecto da corporalidade sob a perspectiva da educação musical, verificamos que educadores do início do século XX criaram novas metodologias de ensino musical que envolveram a prática corporal como ferramenta de ensino.

Além de Dalcroze, podemos citar também Edgar Willems (1890 - 1978), Carl Orff (1895-1982) e Murray Schafer (1933-), entre outros. Estes educadores defenderam a ideia da utilização do corpo para sensibilizar o aluno que estuda música, sendo que seus trabalhos enfatizaram a proximidade entre a prática corporal e o desenvolvimento de estruturas cognitivas. Estes educadores valorizaram a ação corporal, destacando que o verdadeiro ritmo está presente em ações cotidianas do ser humano, tais como: andar, respirar, o pulsar do sistema circulatório e movimentos sutis causados pela emoção ou por pensamentos. Estes educadores defendem que os movimentos instintivos que nos são inerentes podem ser utilizados para despertar a vivência interior do ritmo, como exemplificado abaixo na citação sobre a metodologia criada por Carl Orff:

Na metodologia Orff, o movimento é uma ajuda indispensável para o desenvolvimento de habilidades musicais e a formação de conceitos. Ele ajuda o aluno a assimilar vários aspectos rítmicos como o pulso, modelos ou padrões, medidas e tempos. A direção melódica e qualidades como

\footnotetext{
6 "It was Emile-Jacques Dalcroze who first realized that musical rhythm depends absolutely on motor consciousness for its fuller expression. His researches led him to evolve a system of rhythm movement designed to develop mastery of musical rhythm. This system of music education uses the body as the interpreter of musical rhythm and is known the world over by eurhythmics"
} 
dinâmicas e cores podem ser expressas em movimento e este pode ilustrar texturas, formas e situações dramáticas de modo em concreto. (Lima; Ruger, 2007, p. 105)

Pensando nas diversas abordagens citadas referentes à utilização do corpo no aprendizado musical e em sua importância, destacamos também que tal abordagem é hoje bastante explorada na educação infantil, mas pouco utilizada nos cursos de graduação em música, assim como a prática da improvisação. Considerando ainda a impossibilidade de abordar toda a amplitude do tema da corporalidade, nosso recorte neste artigo será o de abordar apenas a conexão corpo/música mais voltada para o aspecto rítmico. Neste aspecto, observamos que essa mesma conexão é encontrada na música não ocidental, como na música africana e na indiana, aonde há uma profunda relação entre dança e música sob o aspecto rítmico em geral.

Além das conexões entre corpo e música encontrada nas culturas não ocidentais e também em propostas que envolvem novas metodologias na educação musical, podemos ainda observar o crescimento de iniciativas multidisciplinares no cenário da performance ${ }^{7}$.

Em nosso trabalho, as integrações entre música e dança que encontramos na cultura não ocidental, e que foi mais tarde incorporada na metodologia de alguns educadores, também é parte relevante para elaboração dos exercícios que amostraremos ao final deste artigo.

\section{A contribuição da música não ocidental para a criação de ambientes multiculturais}

"Se houvesse uma nova versão da música, esta não viria do ocidente, mas sim do oriente" (Griffiths, 1994, p. 116)

\footnotetext{
7 No Brasil podemos citar como exemplo desta integração os trabalhos de Antônio Nóbrega, Ivaldo Bertazzo e do grupo Barbatuques, entre outros

8 "If there were to be a new release in music, it would come not from the west but from the east"
} 
A partir do início do século XX, especialmente na França, houve o contato de compositores com a cultura não ocidental, vindo tanto por compositores que migraram da Europa oriental para o ocidente (como Béla Bartók [1881-1945], da Hungria e Igor Stravinsky [1882-1971], da Rússia) quanto pelo contato com culturas ancestrais, como as da Índia, África e Indonésia. Neste período, novos elementos estruturais - como configurações escalares provindas da música não ocidental e estruturas polirrítmicas encontradas em regiões da África - passaram a fazer parte dos recursos utilizados por compositores como Claude Debussy (18621918), Maurice Ravel (1875-1937), Olivier Messiaen (1908-1992), Henry Cowell (1897-1965) e Steve Reich (1936-), entre outros.

No que diz respeito à influência da música não ocidental nos ambientes de improvisação no Ocidente, podemos afirmar que ela forneceu novos materiais expressivos e elementos estruturais, como configurações escalares fora do padrão maior/menor e estruturas rítmicas elaboradas, como a polirritmia africana e a tala indiana, promovendo ambientes multiculturais que hoje podemos encontrar na performance em contextos diversos. A música não ocidental trouxe também várias contribuições conceituais à prática da improvisação, relacionando esta atividade a um processo interativo e de escuta atenta, muitas vezes parte de um ritual. Entre estas contribuições podemos também citar as questões relativas ao tempo não linear da improvisação, à circularidade e à improvisação não discursiva.

Tomando por referência o percurso musical em seu aspecto histórico, podemos dizer que o contato com a cultura não ocidental foi uma importante expansão para além das fronteiras da música europeia ocidental. Nesse contexto, desde o início do século XX. músicos saíram em busca de materiais e procedimentos que pudessem enriquecer seus processos criativos, sendo que muitas de suas obras ilustram claramente a influência da música não ocidental. Os músicos que receberam esta influência trabalharam cada qual a seu modo, recriando e expandindo materiais musicais encontrados na cultura não ocidental em seus trabalhos.

Surge então a questão de como, em geral, este conhecimento da música nãoocidental pode influenciar o compositor. A influência menos interessante, a meu ver, é imitar o som de algumas das manifestações da música não- 
ocidental. [...] Alternativamente, pode-se criar uma música de sonoridade própria, construída à luz do conhecimento que o compositor possui sobre estruturas da música não-ocidental. ${ }^{9}$ (Reich apud Hillier, 2002, p. 70)

Nossa ideia aqui não é apenas incorporar e imitar a sonoridade da música não ocidental - como menciona Steve Reich - mas propor a interação e o diálogo com estruturas da música não ocidental da mesma forma que compositores e músicos de gêneros e épocas distintas o fizeram. Assim como a música não ocidental ampliou o leque de procedimentos e materiais utilizados por esses músicos, queremos aqui estender essa mesma ideia de diálogo e interação com a música não ocidental para a educação formal do músico.

Se a MÚSICA consiste em uma variedade de culturas musicais, então a MÚSICA é inerentemente multicultural. E se a MÚSICA é inerentemente multicultural, então a educação musical deveria ser multicultural em sua essência. ${ }^{10}$ (Elliot, 1995, p.207)

Expandindo a ideia de multiculturalidade citada por Elliot, podemos dizer que vivemos uma realidade bastante propícia para tal abordagem. A acessibilidade dos meios de comunicação, as iniciativas multiculturais que encontramos nos ambientes de performance musical e os trabalhos que propõem interações multimidiáticas entre as artes podem ser expandidos para a formação do músico. Pensando também sob a ótica de Steve Reich, observamos que é possível expandir os materiais que hoje encontramos nos cursos de formação de músicos sob esse mesmo viés multicultural, propondo o diálogo com materiais musicais diversos. Desta forma, podemos trazer materiais e procedimentos musicais de outras culturas - aqui especificamente citando alguns procedimentos

\footnotetext{
9 "The question then arises as to how, if at all, this knowledge of non-Western music influences a composer. The least interesting form of influence, to my mind, is that of imitating sound of some non-Western music. [...] Alternatively, one can create a music with own's sound that is constructed in the light of one's knowledge of non-Western structures."

10 "If MUSIC consists in a variety of music cultures, then MUSIC is inherently multicultural. And if MUSIC is inherently multicultural, then music education ought to be multicultural in essence."
} 
da música não ocidental e a prática da improvisação - promovendo práticas que não tem sido muito abordadas nos cursos de graduação em música.

Defendendo portanto a ideia de que a formação do músico pode ser enriquecida se tratada também em contextos multiculturais, vamos fazer uma pequena amostragem de propostas para a preparação e a prática da improvisação do músico a partir de sua graduação.

\section{Propostas de improvisação para alunos da graduação em música}

A amostragem a seguir faz parte de uma pesquisa de doutorado que consiste no estudo e elaboração de propostas de improvisação que se utilizam de materiais expressivos e procedimentos encontrados na música não ocidental. Ao final da pesquisa mencionada, propõe-se que, da mesma forma que os compositores do século XX dialogaram com materiais da música não ocidental, tal diálogo possa se estender à prática e ao estudo da improvisação. Na amostragem que vamos apresentar, partimos de exercícios que envolvem o movimento e a coordenação motora para desenvolver a acuidade rítmica e a capacidade de coordenar a improvisação com o movimento. Em seguida vamos propor que a improvisação seja realizada no instrumento, utilizando compassos assimétricos e configurações modais como padrões de ostinato para esta prática.

Os exercícios aqui descritos foram propostos aos alunos da graduação em música da USP, durante disciplina de improvisação ministrada pelo prof. Rogério Luiz Moraes Costa e em workshop ministrado pelo autor durante o congresso PERFORMA, realizado em maio de 2011 em Aveiro, Portugal. Os exercícios e a pesquisa em questão foram em parte elaborados a partir de cursos e workshops realizados na Guildhall School of Music and Drama ${ }^{11}$, Londres.

A base metodológica de nossa proposta consiste em tratar o processo de improvisação primeiramente por uma vivência corporal, para depois aplicá-lo à

${ }^{11}$ Cursos realizados na Guildhall School: Transcultural Module e CPD Course em 2002 e 2008. 
performance no instrumento, considerando a interação corpo/música inicialmente proposta por Jacques Dalcroze. Além desta premissa, utilizamos materiais da música não ocidental para ampliar esta prática e tratá-la a partir de um enfoque multicultural. Com este enfoque, utilizamos parâmetros como a noção de tempo circular - que é mais encontrada dentro de contextos da música não ocidental e em contextos modais - e as medidas de tempo assimétricas, exploradas por compositores do início do século XX, sob a influência de estruturas rítmicas encontradas na música não ocidental.

Considerando que a proposta é direcionada para alunos de graduação em música, os pré-requisitos exigidos para participar dos exercícios que propomos são os mesmos exigidos para o ingresso nos cursos de graduação: domínio da linguagem musical, domínio da leitura, acuidade auditiva, noções teóricas sobre formação de escalas e modos, noções básicas de harmonia e domínio de um instrumento musical.

A proposta foi elaborada pelo autor a partir de vivência profissional e acadêmica nas áreas de música e dança e de experiências didáticas prévias envolvendo todo tipo de integração entre música e movimento. A ordem escolhida para os exercícios propostos a seguir tem sua linha condutora baseada primeiramente na vivência e internalização de estruturas rítmicas pelo movimento corporal, passando pela experimentação da improvisação pelas vias do movimento e, por fim, a prática da improvisação no instrumento, utilizando materiais expressivos como configurações escalares fora do sistema tonal e compassos assimétricos.

\section{Exercício 1}

No primeiro exercício, com o propósito de preparar o músico para a prática da improvisação, vamos trabalhar a concentração e a acuidade rítmica pela conexão entre ritmo e movimento. Vamos propor a realização de alguns padrões rítmicos em um contexto onde um pulso é subtraído a cada dois compassos, começando pelo compasso de 5/4 até chegar em 2/4. 
Os participantes vão andar para frente e para trás, usando a pulsação de cada compasso (por exemplo: se o compasso for de 5/4, os participantes darão 5 passos para frente e 5 para trás). Os padrões rítmicos descritos abaixo serão realizados com palmas. Dependendo da resposta do grupo, este mesmo exercício pode ser proposto em formato de cânone, podendo ser realizado por dois grupos ou mais, com diferentes medidas de defasagem.

Figura 5 - exercício preparatório para prática da improvisação

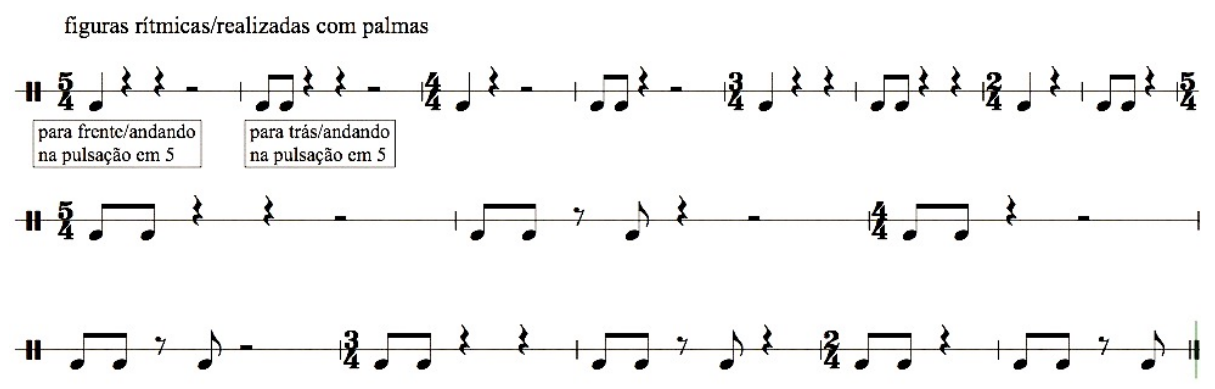

Fonte: exercício criado pelo autor

\section{Exercício 2}

No segundo exercício vamos propor uma improvisação vocal em grupo a partir de um ostinato com um padrão rítmico realizado no compasso de 7/4 (construído em 3/4 e 4/4). Esse ostinato será realizado como percussão corporal, como descrito na figura 6 , sendo que os participantes vão caminhar pelo espaço livremente, realizando o ostinato e a improvisação vocal ao mesmo tempo. Em um primeiro momento sugerimos que os participantes realizem apenas o ostinato até se sentirem confortáveis para que, aos poucos, tentem realizar a improvisação vocal, coordenando o movimento com suas vozes. Neste exercício a improvisação vocal é livre, podendo ser conduzida por estímulos vocais mais percussivos ou mais melódicos, sempre dependendo do grupo com o qual estamos trabalhando. Referente ao material melódico que propomos aqui, sugerimos algumas 
configurações escalares modais e pentatônicas, já pensando na improvisação que será sugerida no instrumento, no próximo exercício.

Figura 6 - Exercício para coordenar movimento e improvisação vocal

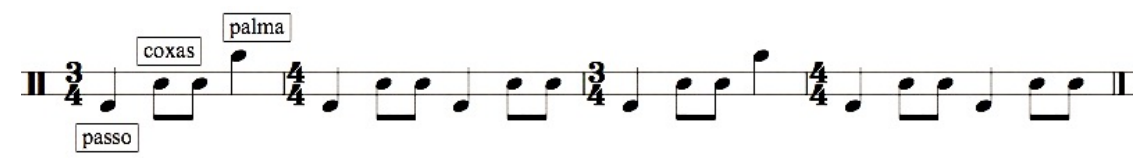

Fonte: exercício criado pelo autor

\section{Exercício 3}

Aqui vamos trabalhar a improvisação com instrumentos musicais, propondo que a improvisação seja realizada a partir de ostinatos baseados em configurações escalares fora do padrão tonal propostos em compassos assimétricos, dando continuidade ao trabalho de preparação descrito nos primeiros exercícios. Neste exercício podemos utilizar configurações escalares diversas - como escalas hexafônicas, escalas pentatônicas extraídas da música javanesa, configurações modais - e assim por diante. A improvisação pode ser realizada individualmente e em grupo. Quando proposta individualmente, o grupo toca o ostinato e cada músico improvisa de acordo com uma ordem previamente estabelecida. Na improvisação em grupo, todo o grupo toca o ostinato em um determinado número de compassos e improvisa no mesmo intervalo de tempo, utilizando as notas da configuração escalar sugerida.

Nessa improvisação podemos sugerir que os participantes explorem aspectos referentes ao timbre, aspectos fraseológicos e, principalmente, a interação com o grupo, mesmo quando a improvisação é proposta individualmente. Nos exemplos abaixo, temos dois ostinatos propostos nos modos Dórico e Lídio. Cadências harmônicas podem também ser sugeridas para complementar a base de acompanhamento para a improvisação: 
Figura 7 - ostinato em modo Dórico

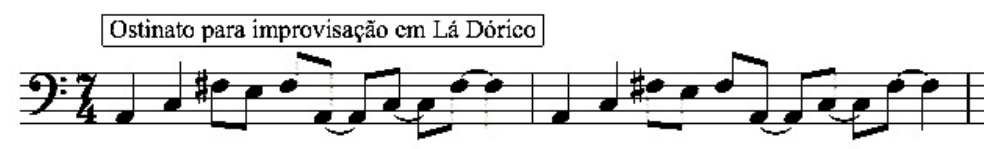

Fonte: exercício criado pelo autor

Figura 8 - ostinato em modo Lídio

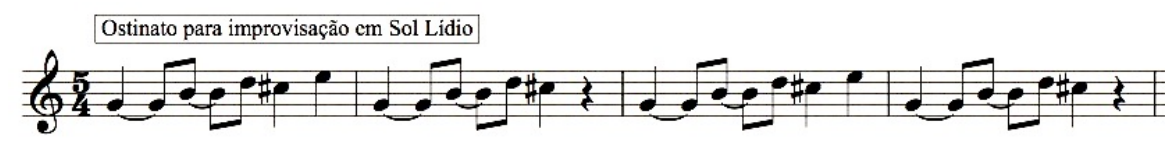

Fonte: exercício criado pelo autor

\section{Considerações finais}

Os exercícios aqui relatados foram aplicados tanto na USP quanto no congresso PERFORMA para estudantes de graduação em música e músicos interessados em desenvolver a prática da improvisação sob os parâmetros aqui mencionados. Tendo por base as primeiras experiências ao aplicar alguns dos exercícios amostrados, pudemos constatar que a abordagem sugerida pôde contribuir para desenvolver aspectos como: concentração, acuidade rítmica, coordenação motora, interação em grupo e desenvolvimento de materiais expressivos para a prática da improvisação em ambientes e contextos diversos.

É importante ressaltar também que a proposta de iniciar a prática de improvisação a partir da corporalidade fez com que os instrumentistas já estivessem com os materiais musicais propostos bastante internalizados ao fim do processo. Tal constatação nos conduz a aprimorar nossa proposta no sentido de dar continuidade ao processo de pesquisa, com o intuito de construir territórios híbridos para o estudo e a prática da improvisação na formação do músico.

Ressaltando a defesa de uma abordagem multicultural no ensino da música em geral, a ideia principal do artigo foi amostrar algumas possibilidades para o estudo da improvisação, enfatizando a importância desta prática em todo e qualquer curso de formação de músicos, incluindo sua graduação e demais 
formações. Pensando também no estudo da improvisação como um todo, podemos dizer que nossa proposta pode enriquecer os materiais já abordados nesta prática, como a sólida escola de improvisação direcionada aos estudos jazzísticos e os estudos sobre a improvisação livre, entre outros.

Concluindo nossas considerações, defendemos a ideia de que a combinação de elementos estruturais, conceituais e expressivos de diferentes formas de improvisação podem trazer uma contribuição relevante na formação do músico do nosso século. Com tal abordagem pretendemos aumentar o espectro deste músico para suas futuras escolhas, considerando os materias e procedimentos musicais que ele poderá utilizar futuramente em sua vida profissional.

\section{Referências}

BAILEY, Derek. Improvisation, its nature and practice in music. England: Da Capo Press, 1993.

ELLIOT, David J. Music matters: a new philosophy of music education. New York: Oxford University Press, 1995.

FINDLAY, Elsa. Rhythm and Movement: applications of Dalcroze eurhythmics. Miami: Summy-Birchard Inc., 1999.

GRIFFITHS, Paul. Modern Music: a concise history. New York: Thames and Hudson Inc., 1994.

HILLIER, Paul (Org.). Steve Reich: Writings on Music (1965-2000). New York: Oxford University Press, 2002.

LIMA, Sonia A.; RUGER, Alexandre C. L. O trabalho corporal nos processos de sensibilização musical. Opus 13, Goiânia, n.1, p. 97-118, 2007.

SOLIS, Gabriel; NETTL, Bruno (Org.). Musical Improvisation: art, education and society. Chicago: University of Illinois Press, 2009.

TITON, Jeff Todd. Worlds of Music: an introduction to the music of the world's peoples. Boston: Thomson Schirmer, 2005. 